\title{
Avaliação do Diagnóstico e Tratamento em Parada Cardiorrespiratória entre os Médicos com mais de Cinco Anos de Graduação*
}

\author{
Assessment of the Diagnostic and Treatment in Cardiac \\ Arrest between Doctors with Five Years after Graduation
}

Fabiano Timbó Barbosa1, Luciano Timbó Barbosa², Andréa de Lima Silva³, Kleyner Leão Gomes da Silva4.

\section{RESUMO}

JUSTIFICATIVA E OBJETIVOS: As novas diretrizes contêm importantes modificações para melhorar à prática de reanimação e a sobrevida de pacientes com parada cardíaca $(\mathrm{PC})$. O objetivo desse estudo foi avaliar o conhecimento teórico a cerca da PC e reanimação cardiopulmonar (RCP) entre os médicos com mais de cinco anos graduação.

MÉTODO: Trata-se de uma pesquisa descritiva com abordagem quantitativa em Hospital de Emergência no Estado de Alagoas. A população foi composta por médicos com mais de cinco anos de graduação. Para a coleta de dados utilizou-se questionário com perguntas sobre o tema. Os resultados foram analisados de conformidade com a literatura sobre parada cardíaca e reanimação cardiopulmonar.

RESULTADOS: Responderam ao questionário 39 pro-

1. Intensivista da Clínica Santa Juliana; Título Superior em Anestesiologia conferido pela Sociedade Brasileira de Anestesiologia

2. Intensivista da Clínica Santa Juliana; Especialista em Clínica Médica pela Sociedade de Medicina de Alagoas;

3. Coordenadora da Unidade de Terapia Intensiva da Clínica Santa Juliana; Intensivista da UTI Coronariana do Hospital da Agroindústria do Açúcar e do Álcool de Alagoas.

4. Graduando da Universidade Federal de Alagoas.

${ }^{*}$ Recebido da Unidade de Terapia Intensiva da Clínica Santa Juliana, Maceió, AL

Apresentado em 29 de setembro de 2006

Aceito para publicação em 07 de novembro de 2006

Endereço para correspondência:

Dr. Fabiano Timbó Barbosa

Rua Comendador Palmeira, 113/202 - Farol

57051-150 Maceió, AL

Fone: (82) 9983-2054

E-mail: fabianotimbo@yahoo.com.br

(C)Associação de Medicina Intensiva Brasileira, 2006 fissionais. O diagnóstico da PC foi corretamente respondido por 76,9\%; e, em um caso clínico houve aumento para $87,2 \%$. As indicações do bicarbonato de sódio foram corretamente respondidas por $30,8 \%$ e a indicação adequada do uso de vasopressina era conhecida por $15,4 \%$ dos participantes.

CONCLUSÕES: Esse estudo revelou alguma deficiência no conhecimento dos médicos quando questionados sobre a terapêutica usada na PCR. Mostrou pouco conhecimento acerca da vasopressina como alternativa à adrenalina e o uso freqüente do bicarbonato de sódio é utilizado de maneira inadequada. O estudo apresentou dados que justificam o treinamento contínuo para médicos com mais de cinco anos de formado.

Unitermos: Parada cardíaca, Reanimação cardiopulmonar, Suporte avançado de vida.

\section{SUMMARY}

BACKGROUND AND OBJECTIVES: New resuscitation guidelines contain significant changes intended to improve resuscitation practice and survival from cardiac arrest. The objective of this study was to evaluate the theoretical knowledge about cardiac arrest (CA) and cardiac and pulmonary resuscitation (CPR) among doctors after five years of the graduation.

METHODS: The questionnaire survey was conducted in an Emergency Hospital in the State of Alagoas. The population was composed of doctors with five years after your graduation. The data was collected with a questionnaire with questions about the theme. The results were analyzed based on bibliographies about CA and CPR.

RESULTS: Thirty-nine professionals answered the questionnaire. The CA diagnostic was correct in $76.9 \%$ and increased to 82.7 when the case report was included. Questions about sodium bicarbonate and vasopressin were correctly answered by $30.8 \%$ and $15.4 \%$ 
of the participants.

CONCLUSIONS: The greatest difficulty reported in this study was on the CA arrest Most of the participants of the survey are not aware of the correct indications of vasopressin and sodium bicarbonate in the CPR. According to this study, a continuing medical education program on CPR for physicians with more than five years of graduations warranted.

Key Words: Advanced cardiac life support, Cardiac arrest, Cardiopulmonary resuscitation.

\section{INTRODUÇÃO}

A parada cardiorrespiratória (PCR), pode ser definida como a cessação súbita e inesperada dos batimentos cardíacos associados a ausência de respiração'. A principal causa de PCR em adultos é a doença cardiovascular. O sucesso da reanimação cardiopulmonar (RCP) que ocorre dentro de um hospital é de apenas $30 \%$, sendo que somente $15 \%$ recebem alta sem nenhuma seqüela neurológica².

O óbito fora do ambiente hospitalar quase sempre ocorre por fibrilação ventricular ${ }^{2,3}$, mas geralmente não está associado a episódio de infarto agudo do miocárdio, ao contrário da PCR que ocorre nos hospitais onde o infarto agudo do miocárdio ou as doenças sistêmicas são os principais responsáveis².

A avaliação do paciente não deve levar mais que 10 segundos ${ }^{4}$ e a ausência de manobras de reanimação em aproximadamente cinco minutos levam a alterações irreversíveis dos neurônios do córtex cerebral ${ }^{5}$.

Cabe ao médico garantir adequadas ventilação e circulação artificial, bem como utilizar adequadamente os fármacos recomendados.

$\mathrm{O}$ conhecimento e atualização quanto às recomendações das novas diretrizes da RCP são essenciais para reduzir a mortalidade associada a PCR dos pacientes de qualquer faixa etária.

O objetivo deste estudo foi avaliar o conhecimento do médico sobre o diagnóstico e tratamento atual da parada cardíaca através de questionário.

\section{MÉTODO}

Trata-se de uma pesquisa descritiva com abordagem quantitativa, desenvolvida em Hospital de Emergência, no Estado de Alagoas, no período de maio a setembro de 2005. O projeto foi aprovado pelo Comitê de Ética em Pesquisa da Fundação Universitária de Ciências da Saúde (Protocolo número 334). Todos os participantes assi- naram o termo de consentimento livre e esclarecido.

A população foi constituída por 39 médicos com mais de cinco anos de graduação. Os participantes foram escolhidos aleatoriamente, tendo como critérios, pertencer à equipe médica do Hospital e concordar livremente em participar do estudo. Para a coleta de dados foi utilizado um questionário estruturado, elaborado pelos autores. O instrumento da pesquisa possuía 10 questões objetivas, sobre o conhecimento de parada cardíaca e reanimação cardiorrespiratória (Anexo 1).

Os resultados foram analisados de conformidade com as citações bibliografias sobre parada cardíaca e reanimação cardiorrespiratória.

\section{RESULTADOS}

Foram entregues 100 questionários, porém apenas 39 foram devolvidos.

A tabela 1 demonstra a relação do conhecimento teórico sobre o diagnóstico e o tratamento da PCR pelos médicos com mais de cinco anos de formação.

Tabela 1 - Conhecimento Teórico dos Médicos sobre o Diagnóstico e Tratamento da PCR

\begin{tabular}{lcc}
\hline Respostas & Acerto (\%) & Erro (\%) \\
\hline Diagnóstico & 76,9 & 23,1 \\
Diagnóstico com caso clínico & 87,2 & 12,8 \\
$1^{\text {a }}$ Conduta: chamar ajuda & 48,7 & 51,3 \\
Vasopressina como alternativa à adre- & 15,4 & 84,6 \\
nalina & & \\
Uso de vasopressina pelo tubo traqueal & 51,3 & 48,7 \\
Não usar desfibrilação para assistolia & 59 & 41 \\
Procurar a causa da RCP & 33,3 & 66,7 \\
Bicarbonato para todos os ritmos & 30,8 & 69,2 \\
Quando o socorrista está acompanha- & 56,4 & 43,6 \\
do & & \\
Quando o socorrista está sozinho & 53,9 & 46,1 \\
\hline
\end{tabular}

Constatou-se que a percentagem de acerto em relação à identificação da PCR foi de 76,9\%, porém quando a mesma pergunta foi realizada, mas considerando um caso clínico o índice subiu para 87,2\%.

A primeira conduta adotada após o diagnóstico foi a de chamar por ajuda em $48,7 \%$ dos entrevistados.

A vasopressina foi considerada como alternativa à adrenalina por $15,4 \%$ dos participantes, enquanto $48,7 \%$ não a utilizariam pelo tubo traqueal. Quando questionados sobre a indicação da desfibrilação ventricular para a assistolia, $41 \%$ responderam que acreditavam nesse procedimento como forma de tratamento para a assistolia. Somente 33,3\% procurariam a causa da PCR quando esta ocorresse por atividade elétrica 
sem pulso.

Com relação ao uso do bicarbonato de sódio $69,2 \%$ o utilizariam em todos os ritmos de parada cardíaca.

A seqüência de massagens e ventilações de 5:1 foi respondida por $56,4 \%$ quando o paciente estava intubado e o socorrista estava acompanhado. Em outra questão a relação de $5: 1$ foi mantida por $53,9 \%$ quando o paciente estava intubado, mas o socorrista estava sozinho.

\section{DISCUSSÃO}

O atendimento da PCR deve ser considerado como conhecimento obrigatório e prioritário de todo profissional de saúde, independente de sua especialidade ${ }^{6}$. O diagnóstico rápido e correto é a chave para o sucesso da reanimação cardiopulmonar (RCP). Os sinais usados para o diagnóstico são: ausência de pulso em grande vaso, inconsciência, cianose e ausência de movimentos respiratórios.

A maioria dos pesquisados (76,9\%), demonstrou usar sinais clínicos e do exame físico para o diagnóstico, e quando usados em caso clínico a porcentagem de acerto subiu para $87,2 \%$. A resposta considerada como correta nessa pesquisa era a ausência de pulso em paciente inconsciente. É dispensável o uso de instrumentos sofisticados para o diagnóstico da PCR, devendo ele ser clínico e gatilho para o início da RCP. Apesar das taxas de sobrevivência ainda pequenas, a RCP persiste como melhor meio para a manutenção da perfusão encefálica e coronariana após $\mathrm{PCR}^{8}$.

$\mathrm{O}$ atual protocolo de tratamento da PCR se divide em suporte básico à vida, suporte avançado à vida e suporte prolongado à vida².

Cabe ao médico garantir acesso às vias aéreas, identificar o ritmo cardíaco, usar adequadamente o desfibrilador e os fármacos para auxiliar no retorno da circulação espontânea.

Apenas $33,3 \%$ dos entrevistados responderam que se preocupariam em identificar as possíveis causas de PCR. As causas reversíveis de PCR são citadas como $6 \mathrm{H}$ e 5T ${ }^{6}$ : hipovolemia, hipóxia, hipocalemia, hipercalemia, hipotermia, hipoglicemia, $\mathrm{H}^{+}$(acidose), tromboembolismo pulmonar, tamponamento cardíaco, tóxicas, tensão no tórax (pneumotórax) e trauma. A despreocupação com a causa da RCP pode levar ao aumento da mortalidade, mesmo em pacientes jovens. Em qualquer dos ritmos deve-se estar atento a correção das causas reversíveis ${ }^{6}$.

Quando questionados sobre a indicação da desfibrilação ventricular, $41 \%$ dos médicos responderam que acreditavam nesse procedimento como forma de tratamento para a assistolia. A fibrilação ventricular é o ritmo de parada mais comum em ambiente extra-hospitalar ${ }^{7-9}$. Esse ritmo e a taquicardia ventricular se resolvem com a desfibrilação ventricular-9, que consiste na aplicação de impulso elétrico no tórax, levando as fibras miocárdicas a funcionarem na mesma fase do potencial de ação com a retomada do ritmo normal pelo nodo sinusal ${ }^{9}$. A literatura vigente considera que a desfibrilação ventricular não é benéfica para a assistolia e seu uso, nessa situação, constitui em erro de conduta. Estudos em animais demonstraram necrose miocárdica ${ }^{9}$. A disposição de três choques seguidos, sem interposição de manobras de RCP foi abandonada por conta do alto grau de sucesso do primeiro choque com os modernos desfibriladores bifásicos ${ }^{8}$. O choque inicial aplicado em aparelho monofásico é de $360 \mathrm{~J}$ e em bifásico deve ser entre 120 e $200 \mathrm{~J}^{6}$. Após uma desfibrilação deve-se iniciar a massagem, pois , o coração não retorna a circulação normal imediatamente após o choque, mesmo que a desfibrilação tenha sido bem sucedida ${ }^{10}$. A seqüência atual é choque - RCP - verificações de ritmo e de pulso ${ }^{8}$. A verificação do ritmo deve ser realizada dois minutos após cada desfibrilaçãó.

Neste estudo somente $15,4 \%$ dos participantes sabiam que a vasopressina poderia ser utilizada como alternativa à adrenalina e $48,7 \%$ não sabiam que ela poderia ser administrada pelo tubo traqueal, mesmo não constando na resposta os fármacos já bem conhecidos para uso por essa via como a adrenalina, atropina e a lidocaína. Foi demonstrado que os pacientes sobreviventes de PCR tinham níveis elevados de vasopressina antes e durante a RCP em relação aos não sobreviventes. Desde então, a administração exógena tem sido recomendada em humanos e em estudos experimentais. A vasopressina parece ser superior em relação à epinefrina para aumentar o fluxo de órgãos nobres ${ }^{11}$. A adrenalina é usada a cada 3 a 5 minutos na dose de $1 \mathrm{mg}$, por via venosa ou intra-óssea e a vasopressina na dose de $40 \mathrm{UI}$ em dose única pelas mesmas vias ${ }^{6}$. Atualmente a vasopressina pode ser usada em todos os ritmos de PCR, uma vez que foi evidenciada resposta satisfatória dos pacientes em assistolia e atividade elétrica sem pulso ao contrário do que se preconizava, que era o uso de vasopressina só para fibrilação ventricular e taquicardia ventricular refratária ${ }^{10}$. O desconhecimento desse fármaco assim como o seu uso inadequado pode ser interpretado como um ponto negativo em relação ao sucesso da reanimação. Ainda mais grave seria, se o desconhecimento levasse ao 
baixo uso da vasopressina, mesmo estando esse fármaco presente no arsenal terapêutico dos hospitais.

Esta pesquisa mostrou que $69,2 \%$ dos participantes usariam bicarbonato de sódio em todos os ritmos de parada cardíaca. O conhecimento de outrora, em que a acidose exercia efeitos deletérios sobre o miocárdio levou ao uso indiscriminado do bicarbonato de sódio. O bicarbonato combina-se com o íon hidrogênio e forma o gás carbônico que migra para o interior das células cerebrais e miocárdicas e piora a acidose intracelular ${ }^{7,9}$. Conforme medidas pelo lactato e pelo déficit de bases sangüíneas, a acidose não se torna grave durante 15 a 20 minutos de PCR ${ }^{9}$. Estudo da década de 1970 demonstrou que o uso de $180 \mathrm{mEq}$ em pacientes com PCR resultou em $100 \%$ de mortalidade ${ }^{11}$. Atualmente, o bicarbonato possui indicações restritas que são: hiperpotassemia preexistente conhecida (Classe I), acidose metabólica grave prévia a PCR responsiva ao bicarbonato (Classe lla), overdose de tricíclicos (Classe lla), alcalinização da urina em overdose de alguns fármacos (Classe Ila), retorno a circulação espontânea após RCP prolongada (Classe llb) e acidose lática hipóxica (Classe III) ${ }^{6}$. Em qualquer dos ritmos a dose de $1 \mathrm{mEq} / \mathrm{kg}$ pode ser utilizada, exceto na acidose lática hipóxica que estaria absolutamente contra-indicada ${ }^{6}$, entretanto, mesmo com essa dose se faz necessário pesquisar as suas indicações. Alguns participantes justificaram informalmente seu uso em casos de PCR não bem sucedida, após períodos prolongados de RCP, como último recurso. Como a grande maioria não se preocupa em pesquisar as causas reversíveis de PCR, pode-se inferir que o uso de bicarbonato não estaria justificado.

Neste estudo $56,4 \%$ dos participantes responderam que a seqüência de compressões e ventilações seria de 5:1 quando o paciente estivesse intubado e o socorrista estivesse acompanhado por outro socorrista e 53,4\% manteriam esse padrão se estivessem sozinhos no atendimento. A seqüência de compressões e ventilações de 5:1 foi aceita como conduta correta na época da pesquisa em algumas situações e, por isso foi respondida como correta por alguns dos participantes. Hoje se dá grande ênfase a manutenção das compressões torácicas praticamente sem interrupções ${ }^{6,10}$. A compressão torácica garante fluxo de $50 \%$ do valor normal para os órgãos acima do diafragma, porém baixo fluxo aos órgãos abaixo dele ${ }^{9}$. A recomendação atual é fazer 30:2 em pacientes adultos e crianças atendidas por um ou dois socorristas. Quando houver garantia de vias aéreas as compressões se tornam ininterruptas. Essa alteração visa dar mais ênfase a manutenção da circulação ao mesmo tempo em que previne o aparecimento de complicações relacionadas à ventilação, como o aumento das pressões intratorácica e intra-abdominal ${ }^{8,10}$. Alguns estudos têm demonstrado a eficácia de dispositivos de compressão torácica capazes de gerar freqüência de massagens consistente ${ }^{8}$.

Observou-se que $48,7 \%$ dos médicos responderam que chamariam ajuda antes de iniciarem as manobras de reanimação. As evidências mostraram que quando o socorro é realizado nos primeiros 5 minutos da PCR não há diferença na sobrevida se as manobras iniciarem primeiro ou se a ajuda for solicitada antes de realizadas as manobras. Quando o socorro iniciar depois desse prazo deve-se solicitar ajuda e depois iniciar a RCP, exceto quando o paciente for criança, pois, a principal causa de PCR nessa faixa etária é a hipóxia que exige socorro imediato ${ }^{10}$.

Este estudo possui algumas limitações que merecem alguns comentários. O número de participantes foi pequeno e pode não representar com fidedignidade o conhecimento dos médicos com mais de cinco anos de formação sobre o diagnóstico e o tratamento da PCR. Apenas uma instituição participou da pesquisa, e embora essa instituição seja de referência para emergências no estado de Alagoas, não é possível dizer que os médicos com o mesmo tempo de formação de que em outras instituições tenha o mesmo grau de aprendizado. O pequeno número de questões pode ter sido insuficiente para abordar todos os detalhes relacionados ao assunto e isso pode ter comprometido os resultados. A aplicação de um questionário não constitui um método ideal para avaliar o conhecimento dos profissionais, porém é uma alternativa interessante como passo inicial para pesquisas maiores. Há necessidade de estudos maiores envolvendo o profissional na sua atividade prática para de fato avaliar o grau de conhecimento sobre o assunto pesquisado.

\section{CONCLUSÃO}

Esse estudo revelou alguma deficiência no conhecimento dos médicos quando questionados sobre a terapêutica usada na PCR. Mostrou pouco conhecimento sobre a vasopressina como alternativa à adrenalina e o uso freqüente do bicarbonato de sódio contrariando as novas diretrizes.

Mesmo com as limitações deste estudo acredita-se que este trabalho pode justificar e incentivar a realização de treinamentos mais freqüentes para os médicos com mais de cinco anos de formação. 
Anexo 1

Questionário da pesquisa

Iniciais no nome:

Data:

Idade:

Hospital em que trabalha:

Este trabalho refere-se a(o) paciente adulto(a), não grávida e em parada cardiorrespiratória - PCR.

1. Como se faz o diagnóstico da parada cardiorrespiratória?

- Quando o paciente não responder ao chamado;

Pela ausência de pulso radial;

- Paciente inconsciente e sem pulso carotídeo;

- Pela ausência de incursões torácicas;

Não sei responder.

2. O paciente deu entrada em seu serviço com eliminação de secreção rósea e espumosa pela cavidade oral. Familiar refere passado de estenose mitral sem tratamento. Ao exame físico percebeu-se que o paciente não apresentava incursões torácicas e ficou evidenciada a ausência de todos os pulsos. Pode-se afirmar que

P Paciente chegou em PCR;

- Ausência de pulsos não ajuda no diagnóstico;

- Só se pode fazer o diagnóstico de PCR após a instalação de monitor cardíaco;

- Paciente não está em PCR;

ㄱão sei responder.

3. No hospital ou em serviço de emergência, a primeira conduta após o diagnóstico de PCR é:

I Instalar monitorização;

U Usar adrenalina venosa pelo tubo traqueal;

- Acesso venoso;

Intubar o paciente;

- Chamar ajuda;

- Não sei responder.

4. Paciente em PCR por fibrilação ventricular refratária deve ser tratado com:

$\square$ Atropina;

B Bicarbonato de sódio;

- Vasopressina;

Adenosina;

Não sei responder.

5. Paciente em PCR por assistolia não responde a:

- Massagem cardíaca externa;

Adrenalina;

Desfibrilação ventricular;

Atropina;

Não sei responder.

6. Paciente em PCR por atividade elétrica sem pulso apresenta os melhores resultados às manobras de reanimação quando:

- Usa-se vasopressina;

- Realiza-se cardioversão elétrica.

U Usa-se bicarbonato de sódio;

C Corrigem as causas de PCR;

- Não sei responder.

6. Marque a alternativa errada em relação à PCR.

- Em caso de fibrilação ventricular a amiodarona pode ser usada para o tratamento;

- A desfibrilação faz parte do suporte básico a vida;

- O bicarbonato deve ser usado em todos os ritmos de PCR;

- A atropina pode ser utilizada no tratamento da atividade elétrica sem pulso;

Não sei responder. 


\section{AVALIAÇÃO DO DIAGNÓSTICO E TRATAMENTO EM PARADA CARDIORRESPIRATÓRIA ENTRE OS MÉDICOS COM MAIS DE CINCO ANOS DE GRADUAÇÃO}

7. Quando o paciente está sendo socorrido por um reanimador, mas encontra-se intubado, a seqüência de massagens e ventilações, respectivamente é:
口 5:2;
口 5:1;
- 15:2;
口 15:1;
口 Não sei responder.

8. Quando o paciente está sendo socorrido por dois reanimadores, mas encontra-se intubado, a seqüência de massagens e ventilações, respectivamente é:
- 5:2;
( $5: 1 ;$
口 15:2;
口 15:1;
ㄱão sei responder.

9. Qual o fármaco que pode ser administrada pelo tubo traqueal?

- Sulfato de magnésio;

V Vasopressina;

- Procainamida;

B Bretílio;

口 Não sei responder.

\section{REFERÊNCIAS}

01. Barbosa FT - Parada Cardíaca, em: Barbosa FT - Medo de Anestesia? Por quê? Alagoas, Edufal, 2005;127-132.

02. Pereira HA, Neto PO - Reanimação Cardiopulmonar e Cerebral, em: Nacul FE - Medicina Intensiva Abordagem Prática. Rio de janeiro, Revinter, 2004;91-96.

03. Marino PL - Parada Cardíaca, em: Marino PL - Compêndio de UTI. $2^{\mathrm{a}}$ Ed, Porto Alegre, Artmed, 2000;218-232.

04. SBV para provedores de saúde. Tradução: Andréa JA. American Heart Association: Fundação Interamericana do Coração. Rio de Janeiro, 2002.

05. Zanini J, Nascimento ERP, Barra DCC - Parada e reanimação cardiorrespiratória: conhecimentos da equipe de enfermagem em unidade de terapia intensiva. RBTI, 2006;18:143-147.

06. Feitosa-Filho GS, Feitosa GF, Guimarães HP et al - Atualização em reanimação cardiopulmonar: o que mudou com as novas diretrizes! RBTI, 2006;18:177-185.
07. Ferez D - Reanimação Cardiorrespiratória e Cerebral, em: Yamashita AM, Takaoka F, Auler Júnior JOC et al - Anestesiologia. São Paulo, $5^{\text {a }}$ Ed, Atheneu, 2001;1095-1128.

08. Dias LC, Mendes LCM, Mello PMVC et al - Ruptura gástrica por reanimação cardiopulmonar: Relato de Caso. RBTI, 2006;18:207-211.

09. Otto CW - Ressuscitação Cardiopulmonar, em: Barash PC, Cullen BF, Stoelting RK - Anestesia Clínica. São Paulo, 4ª Ed, Manole, 2004;14851506.

10. Aspectos mais relevantes das diretrizes da American Heart Association sobre ressuscitação cardiopulmonar e atendimento cardiovascular de emergência. Tradução: Marques FRB, Paiva E, Timerman S. American Heart Association/; Fundação Interamericana do Coração e Instituto do Coração. Rio de Janeiro, 2005.

11. Treschan TA, Peters $\mathrm{J}$ - The vasopressin system: physiology and clinical strategies. Anesthesiology, 2006;105:599-612.

12. Abrão J, Gonçalves JGF - Parada cardiorrespiratória: aspectos atuais. Rev Bras Anestesiol, 2000;50:128 -133. 